\title{
A Routing Model for Hybrid Hub-and-Spoke with Time Windows
}

\author{
Felix Arya Gunadi a*, J. Dharma Lesmono b, Kinley Aritonang c \\ a Departement of Industrial Engineering, Parahyangan Catholic University, Indonesia \\ Jl. Ciumbuleuit No 94, Bandung, Indonesia \\ b Departement of Mathematics, Parahyangan Catholic University, Indonesia \\ Jl. Ciumbuleuit No 94, Bandung, Indonesia \\ c Departement of Industrial Engineering, Parahyangan Catholic University, Indonesia \\ Jl. Ciumbuleuit No 94, Bandung, Indonesia \\ *Correspondence author: felixaryagunadi@gmail.com
}

\section{ARTICLE INFO}

\section{Article history}

Received July 24, 2019

Revised February 23, 2020

Accepted February 26, 2020

Available Online February 28, 2020

Keywords

Hybrid hub-and-spoke

Routing problem

Backhauling

Time windows

\begin{abstract}
Currently, the company competition is getting tighter. Distribution companies need to provide excellent service to their customers to maintain their competitiveness. Distribution service performance could be measured with lead time. However, Reducing lead times may increase costs. This problem could be solved using freight consolidation and reducing backhaul. Freight consolidation can be done by using a hub-and-spoke network with a combination of inbound and outbound distribution. This study developed a route model for hybrid hub-and-spoke with time windows. This model determined the routes for shipping goods to consumers and taking products to suppliers using the same vehicle to reduce the backhaul. This model also conducted freight consolidation at the hub. The decision variables in this model included the routes of delivery to consumers, the collection of goods at the suppliers, the number of products distributed through the hub and direct shipping, and the excellent distribution route. This model was implemented into the problems. Besides, a sensitivity analysis of the model was carried out.
\end{abstract}

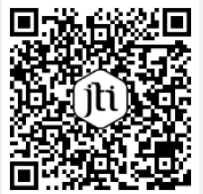

This is an open-access article under the CC-BY-SA license.

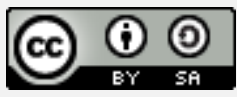

\section{Introduction}

Currently, competition among companies is getting tighter. In order to be competitive, distribution companies need to provide excellent service to customers. The distribution service performance can be measured with lead time. However, the reduction of lead time can result in the underutilization of a vehicle [1]. It may increase transportation costs significantly. Moreover, distribution companies in Indonesia deal with inbound and outbound distribution with separate fleets. They use a particular fleet to deal with outbound distribution, and another fleet deals with inbound distribution. It causes a backhaul as the fleet used to pick up goods at the suppliers is empty when they depart. Meanwhile, the fleet for delivering the products to the customers is also vacant as 
going back to the depot. The reduction of lead time may cause an increase in transportation costs. Therefore, it is necessary to develop a strategy to reduce backhaul, increase vehicle utilization, and reduce lead time [1]. Combining routing strategy inbound and outbound with hub-and-spoke consolidation may solve the problems.

Research on the route was firstly introduced by Dantzig and Ramser in 1959 [2]. The problem is called the Vehicle Routing Problem (VRP). Since then, studies on variations of VRP have emerged. There have been some variations of models developed to solve VRP. Imran and Okdinawati [3], Toth and Vigo [4], Shi, et.al. [5] have developed a heuristic approach to solve VRP. There have also been some studies aiming at solving VRP with time windows (VRPTW), such as El-Sherbeny [6], Liu and Jiang [7], and Ayu and Putri [8]. These variations consider the time windows of customers in determining the routes. Li and Liu [9], Goetschalckx and Jacobs-Blecha [10], Saremi [11] developed another variation of VRP called Vehicle Routing Problem with Backhaul (VRPB). They determine routes to deliver goods to customers and pick up goods at the supplier's using the same fleet. The combination of the abovementioned variations of VRP, also called VRP with backhaul and time windows, has been investigated by Koch, et al. [12], Gupta [13].

There have been various studies on hub-and-spoke. Enis and Mehmet [14] proposed a new multi-objective mathematical model for the newly constructed hub and spoke system. Zhalecian, et al. [15] suggested a new framework to design a hub network under the operational disruption risks. Alkaabneh, et al. [16] proposed a model for hybrid huband-spoke network design with inter-hub economic scale and hub congestion. Lee and Moon [17] solved a problem about a hub-and-spoke scheme in Korean postal logistics with realistic restrictions; they determined the location of the hub and flow of the goods. Chen, et al.[18] formulated a model to optimize the operational cost of a hub-and-spoke network operation for less than the truckload transportation service; the model also incorporated the incremental quantity discount. Yan, et al. [19] formulated a model that determines the transportation volume between distribution groups. There have been some studies that focus on determining routes for hybrid the hub-and-spoke scheme. Liu, et al. [20] formulated a model that determines the route that allows both hub-and-spoke and direct delivery shipment modes. Jian, et al. [21] developed a model that determines the transshipment route of similar products with various vehicle capacities in the hub-andspoke scheme. Wasner and Zäpfel [22] formulated a model that determines the route of pickup, delivery, and transshipment in the hub-and-spoke scheme.

As mentioned earlier, many kinds of research have studied VRP and the hub-andspoke scheme. However, none of them develops a model that can determine a route to deliver and pick up goods using the same fleet and route for distribution. Moreover, there have not been any studies using the hub-and-spoke scheme considering time windows at customers and suppliers (time restriction at the hub that can change depending on the number of products). This research aims at developing a model to determine the route for hybrid hub-and-spoke with time windows. There are several important areas where this study makes its original contribution to the new routing model for the hybrid hub-andspoke with time windows. This research covers five sections, including introduction, model formulation, implementation and sensitivity analysis, result and discussion, and conclusion. The introduction describes the background of problems and state-of-the-art of the study. The formulation of the model is to be discussed in section two. The model is presented in the implementation section and then followed with the sensitivity analysis. The results and discussion section discusses the findings of the implementation analysis and model sensitivity. Finally, the results will be explained in conclusion. 


\section{Methods}

\subsection{Assumptions, Notations, and Model Formulation}

The assumptions of the model comprise of 1 ). The constructed model only uses one hub as a consolidation center; 2). The model's performance is measured with the transportation expenses that incorporate only gas and vehicle usage costs. 3). The loading and unloading times are ignored; 4). The demand is deterministic, and 5). The sorting time/ unit is deterministic. The notations used in this model include:

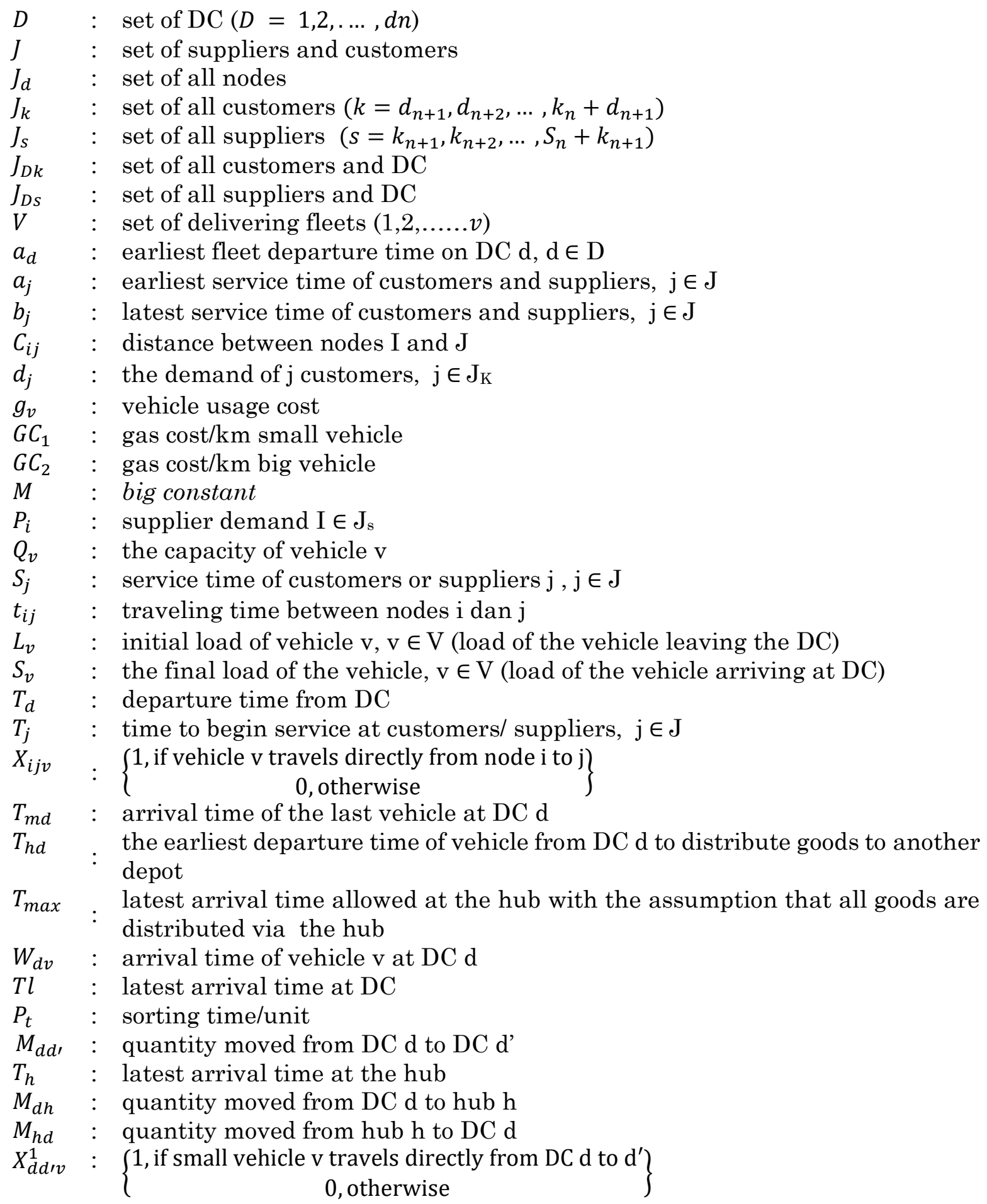


$X_{d d^{\prime} v}^{2}:\left\{\begin{array}{c}1, \text { if big vehicle } \mathrm{v} \text { travels directly from } \mathrm{DC} \mathrm{d} \text { to } \mathrm{d}^{\prime} \\ 0, \text { otherwise }\end{array}\right\}$

$D_{h} \quad$ : set of DC and hub $\left(1,2, \ldots . d_{n+1}\right)$

$H \quad$ : index of hub $\left(d_{n+1}\right)$

$n \quad:$ quantity of vehicle for distribution at each DC

$V_{n} \quad$ : the sum of all vehicle for distribution purpose $(1,2, \ldots . n \times d)$

$V_{n 1} \quad$ : distribution vehicle DC $1\left(1,2, \ldots \ldots n_{1}\right)$

$V_{n 2} \quad:$ distribution vehicle DC $2\left(n_{1+1}, n_{1+2}, \ldots n_{2}\right)$

$V_{n 3} \quad$ : distribution vehicle DC $3\left(n_{2+1}, n_{2+2}, \ldots n_{3}\right)$

$K^{1} \quad$ : small vehicle capacity

$K^{2} \quad$ : big vehicle capacity

The model is developed based on Saremi [11] and Liu, et al. [20]. This model has four decision variables. Three decision variables are to determine the route of a vehicle, such as $X_{i j v}, X_{d d^{\prime} v}^{1}$, and $X_{d d v v}^{2} . X_{i j v}$ is a decision that arranges the route of shipping the goods to customers and pick up the goods. $X_{d d / v}^{1}$ refers to a decision to arrange small vehicle routes for transshipment in the hub-and-spoke network. $X_{d d / v}^{2}$ is a decision that organizes the big vehicle route for transshipment in the hub-and-spoke network. One decision variable determines whether the distribution is carried via a hub or direct shipping along with the quantity. The objective function of this model is to minimize the total costs, including vehicle usage cost $(V C)$ and transportation cost (TC). The following is the route determination model for the hybrid hub-and-spoke distribution network.

\section{Objective Function}

Minimize $V C+T C$

Where:

$\mathrm{VC}=\sum_{\mathrm{d} \in \mathrm{D}} \sum_{\mathrm{v} \in \mathrm{V}} \sum_{\mathrm{j} \in \mathrm{J}} \mathrm{g}_{1} \mathrm{X}_{\mathrm{djv}}+\sum_{\mathrm{d} \in \mathrm{D}} \sum_{\mathrm{v} \in \mathrm{Vn}} \sum_{\mathrm{d}^{\prime} \in \mathrm{Dh}, \mathrm{d} / \neq \mathrm{d}} \mathrm{g}_{1} \mathrm{X}_{\mathrm{dd} / \mathrm{v}}^{1} \mathrm{~V}_{\mathrm{dv}}+\sum_{\mathrm{d} \in \mathrm{D}} \sum_{\mathrm{v} \in \mathrm{Vn}} \sum_{\mathrm{d}^{\prime} \in \mathrm{Dh}, \mathrm{d} / \neq \mathrm{d}} \mathrm{g}_{2} \mathrm{X}_{\mathrm{dd} / \mathrm{v}}^{2} \mathrm{~V}_{\mathrm{dv}}$

$\mathrm{TC}=\sum_{\mathrm{i} \in \mathrm{Jd}} \sum_{\mathrm{j} \in \mathrm{J}} \sum_{\mathrm{v} \in \mathrm{V}} \mathrm{X}_{\mathrm{ijv}} \mathrm{C}_{\mathrm{ij}} \mathrm{GC}_{1}+\sum_{\mathrm{d} \in \mathrm{Dh}} \sum_{\mathrm{d}^{\prime} \in \mathrm{dh}, \mathrm{d}^{\prime} \neq \mathrm{d}} \sum_{\mathrm{v} \in \mathrm{V}} \mathrm{X}_{\mathrm{dd} d^{\prime}}^{1} \mathrm{CC}_{\mathrm{ij}} \mathrm{GC}_{1}+\sum_{\mathrm{d} \in \mathrm{Dh}} \sum_{\mathrm{d}^{\prime} \in \mathrm{dh}, \mathrm{d} / \neq \mathrm{d}} \sum_{\mathrm{v} \in \mathrm{V}} \mathrm{X}_{\mathrm{dd} / \mathrm{v}}^{2} \mathrm{CC}_{\mathrm{ij}} \mathrm{GC}_{2}$

\section{Subject to}

$$
\begin{aligned}
& \sum_{\mathrm{i} \in \mathrm{d} d} \sum_{\mathrm{v} \in \mathrm{V}} \mathrm{X}_{\mathrm{jiv}}=1 \quad \forall \mathrm{j} \in \mathrm{J} \\
& \sum_{\mathrm{i} \in J \mathrm{~d}} \mathrm{X}_{\mathrm{ijv}}=\sum_{\mathrm{i} \in \mathrm{Jd}} \mathrm{X}_{\mathrm{jiv}} \forall \mathrm{j} \in \mathrm{J}, \quad \forall \mathrm{v} \in \mathrm{V} \\
& \sum_{\mathrm{j} \in \mathrm{J}} \mathrm{X}_{\mathrm{djv}}=\sum_{\mathrm{j} \in \mathrm{J}} \mathrm{X}_{\mathrm{jdv}} \forall \mathrm{v} \in \mathrm{V}, \forall \mathrm{d} \in \mathrm{D} \\
& \sum_{\mathrm{i} \in \mathrm{D}} \sum_{\mathrm{j} \in \mathrm{J}} \mathrm{X}_{\mathrm{jiv}}=1 \quad \forall \mathrm{v} \in \mathrm{V} \\
& \mathrm{Q}_{\mathrm{v}} \geq \sum_{\mathrm{i} \in \mathrm{Jdk}} \sum_{\mathrm{J} \in \mathrm{Jk}} \mathrm{d}_{\mathrm{j}} \mathrm{X}_{\mathrm{ijv}} \quad \forall \mathrm{v} \in \mathrm{V} \\
& \mathrm{Q}_{\mathrm{v}} \geq \sum_{\mathrm{i} \in \mathrm{Js}} \sum_{\mathrm{J} \in \mathrm{Jds}} \mathrm{P}_{\mathrm{i}} \mathrm{X}_{\mathrm{ijv}} \quad \forall \mathrm{v} \in \mathrm{V} \\
& \mathrm{T}_{\mathrm{j}} \geq \mathrm{T}_{\mathrm{dv}}+\mathrm{t}_{\mathrm{dj}}-\mathrm{M}\left(1-\mathrm{X}_{\mathrm{djv}}\right) \forall \mathrm{j} \in \mathrm{J}, \forall \mathrm{v} \in \mathrm{V}, \forall \mathrm{d} \in \mathrm{D} \\
& T_{j} \geq T_{i}+S_{i}+t_{i j}-M\left(1-\sum_{v \in V} X_{i j V}\right) \forall i \in J, \forall j \in J \\
& \mathrm{a}_{\mathrm{d}} \leq \mathrm{T}_{\mathrm{dv}} \quad \forall \mathrm{v} \in \mathrm{V}, \forall \mathrm{d} \in \mathrm{D} \\
& a_{j} \leq T_{j} \leq b_{j} \forall j \in J \\
& \sum_{\mathrm{J} \in \mathrm{Jk}} \sum_{\mathrm{v} \in \mathrm{V}} \mathrm{X}_{\mathrm{ijv}}=0 \quad \forall \mathrm{i} \in \mathrm{J}_{\mathrm{S}} \\
& \sum_{\mathrm{i} \in \mathrm{d}} \sum_{\mathrm{j} \in \mathrm{d} \mathrm{j} \neq \mathrm{i}} \mathrm{X}_{\mathrm{ijv}}=0 \quad \forall \mathrm{v} \in \mathrm{V} \\
& \sum_{\mathrm{i} \in \mathrm{s}} \sum_{\mathrm{j} \in \mathrm{s}, \mathrm{j} \neq \mathrm{i}} \mathrm{X}_{\mathrm{ijv}} \leq|\mathrm{s}|-1 \quad \forall \mathrm{s} \in \mathrm{J},|\mathrm{s}| \geq 2, \forall \mathrm{v} \in \mathrm{V}
\end{aligned}
$$




$$
\begin{aligned}
& \mathrm{W}_{\mathrm{dv}}=\sum_{\mathrm{i} \in J_{\mathrm{k}}}\left(T_{\mathrm{i}}+\mathrm{S}_{\mathrm{i}}+\mathrm{t}_{\mathrm{id}}\right) \times \mathrm{X}_{\mathrm{idv}} \forall \mathrm{v} \in \mathrm{V} \\
& \operatorname{Tm}_{\mathrm{d}}=\operatorname{Max}\left(\mathrm{W}_{\mathrm{d} 1}, \ldots . ., \mathrm{W}_{\mathrm{dv}}\right) \forall \mathrm{d} \in \mathrm{D} \\
& \mathrm{Tn}_{\mathrm{d}}=\mathrm{Tm}_{\mathrm{d}}+\left(\operatorname{Pt} \times \sum_{\mathrm{d}^{\prime} \in \mathrm{D}, \mathrm{d} \prime \neq \mathrm{d}} \mathrm{m}_{\mathrm{dd}}\right) \forall \mathrm{d} \in \mathrm{D} \\
& \mathrm{Th}=\operatorname{Tmax}+\left(\mathrm{Pt} \times \sum_{\mathrm{d} \in \mathrm{D}} \sum_{\mathrm{d}^{\prime} \in \mathrm{d}, \mathrm{d} l \neq \mathrm{d}} \mathrm{mdd}^{\prime}\right) \\
& \mathrm{m}_{\mathrm{dh}}+\sum_{\mathrm{d}^{\prime} \in \mathrm{d}, \mathrm{d} / \neq \mathrm{d}} \mathrm{m}_{\mathrm{dd},}=\sum_{\mathrm{d}^{\prime} \in \mathrm{d}, \mathrm{d} / \neq \mathrm{d}} \mathrm{M}_{\mathrm{dd},}, \forall \mathrm{d} \in \mathrm{D} \\
& \mathrm{m}_{\mathrm{hd}}+\sum_{\mathrm{d}^{\prime} \in \mathrm{d}, \mathrm{d} / \neq \mathrm{d}} \mathrm{m}_{\mathrm{d} / \mathrm{d}}=\sum_{\mathrm{d}^{\prime} \in \mathrm{d}, \mathrm{d} / \neq \mathrm{d}} \mathrm{M}_{\mathrm{d}^{\prime} / \mathrm{d}} \forall \mathrm{d} \in \mathrm{D} \\
& \mathrm{m}_{\mathrm{dd}} \leq \sum_{\mathrm{v} \in \mathrm{V}}\left(\mathrm{X}_{\mathrm{dd}^{\prime} \mathrm{v}}^{2}+\mathrm{X}_{\mathrm{d}^{\prime} \mathrm{dv}}^{2}\right) * \mathrm{~K}^{2}+\sum_{\mathrm{v} \in \mathrm{V}}\left(\mathrm{X}_{\mathrm{dd}^{\prime} \mathrm{v}}^{1}+\mathrm{X}_{\mathrm{\prime d}^{\prime} \mathrm{dv}}^{1}\right) * \mathrm{~K}^{1} \forall \mathrm{d} \in \mathrm{D}, \forall \mathrm{d}^{\prime} \in \mathrm{D}, \mathrm{d}^{\prime} \neq \mathrm{d} \\
& \mathrm{m}_{\mathrm{dh}} \leq \sum_{\mathrm{v} \in \mathrm{V}} \mathrm{X}_{\mathrm{dhv}}^{2} * \mathrm{~K}^{2}+\sum_{\mathrm{v} \in \mathrm{V}} \mathrm{X}_{\mathrm{dhv}}^{1} * \mathrm{~K}^{1} \forall \mathrm{d} \in \mathrm{D} \\
& \sum_{\mathrm{v} \in \mathrm{V}} \mathrm{X}_{\mathrm{dd}^{\prime} \mathrm{v}}^{2}=\sum_{\mathrm{v} \in \mathrm{V}} \mathrm{X}_{\mathrm{d}^{\prime} \mathrm{dv}}^{2}, \sum_{\mathrm{v} \in \mathrm{V}} \mathrm{X}_{\mathrm{dd}^{\prime} \mathrm{v}}^{1}=\sum_{\mathrm{v} \in \mathrm{V}} \mathrm{X}_{\mathrm{d}^{\prime} \mathrm{dv}}^{1} \forall \mathrm{d} \in \mathrm{D}, \forall \mathrm{d}^{\prime} \in \mathrm{D}, \mathrm{d}^{\prime} \neq \mathrm{d} \\
& \sum_{\mathrm{d} \ell \in \mathrm{Dh}} \mathrm{X}_{\mathrm{dd} / \mathrm{v}}^{1}=\sum_{\mathrm{d} / \in \mathrm{Dh}} \mathrm{X}_{\mathrm{d} / \mathrm{d} \mathrm{v}}^{1} \forall \mathrm{d} \in \mathrm{d}, \forall \mathrm{v} \in \mathrm{V} \\
& \sum_{\mathrm{d} \ell \in \mathrm{Dh}} \mathrm{X}_{\mathrm{dd} / \mathrm{v}}^{2}=\sum_{\mathrm{d}, \in \mathrm{Dh}} \mathrm{X}_{\mathrm{d} / \mathrm{dv}}^{2} \forall \mathrm{d} \in \mathrm{d}, \forall \mathrm{v} \in \mathrm{V} \\
& \sum_{\mathrm{d} \ell \in \mathrm{Dh}} \mathrm{X}_{\mathrm{dd} / \mathrm{v}}^{1} \leq 1 \quad \forall \mathrm{d} \in \mathrm{D}, \forall \mathrm{v} \in \mathrm{V} \\
& \sum_{\mathrm{d} / \in \mathrm{Dh}} \mathrm{X}_{\mathrm{dd} / \mathrm{v}}^{2} \leq 1 \quad \forall \mathrm{d} \in \mathrm{D}, \forall \mathrm{v} \in \mathrm{V} \\
& \mathrm{V}_{\mathrm{dv}}=\left\{\begin{array}{c}
1, \text { if vehicle } \mathrm{v} \text { came from } \mathrm{d} \\
0, \text { If not }
\end{array}\right. \\
& \mathrm{Twh}_{\mathrm{dv}}^{1} \geq\left(\left(1-\mathrm{V}_{\mathrm{dv}}\right) \sum_{\mathrm{i} \in \mathrm{D}, \mathrm{i} \neq \mathrm{d}}\left(\mathrm{Tn}_{\mathrm{d}}+\mathrm{TT}_{\mathrm{id}}\right) \times \mathrm{X}_{\mathrm{idv}}^{1}\right)+\left(\mathrm{V}_{\mathrm{dv}}\left(\sum_{\mathrm{i} \in \mathrm{D}, \mathrm{i} \neq \mathrm{d}} \mathrm{Twh}_{\mathrm{id}}^{1}+\mathrm{TT}_{\mathrm{id}}+\left(\mathrm{Pt} \times \mathrm{m}_{\mathrm{id}}\right)\right) \times \mathrm{X}_{\mathrm{idv}}^{1} \forall \mathrm{d} \in\right. \\
& \mathrm{Dh}, \forall \mathrm{v} \in \mathrm{V}
\end{aligned}
$$

$\mathrm{Twh}_{\mathrm{dv}}^{2} \geq\left(\left(1-\mathrm{V}_{\mathrm{dv}}\right) \sum_{\mathrm{i} \in \mathrm{D}, \mathrm{i} \neq \mathrm{d}}\left(\mathrm{Tn}_{\mathrm{d}}+\mathrm{TT}_{\mathrm{id}}\right) \times \mathrm{X}_{\mathrm{idv}}^{2}\right)+\left(\mathrm{V}_{\mathrm{dv}}\left(\sum_{\mathrm{i} \in \mathrm{D}, \mathrm{i} \neq \mathrm{d}} \mathrm{Twh}_{\mathrm{id}}^{2}+\mathrm{TT}_{\mathrm{id}}+\left(\mathrm{Pt} \times \mathrm{m}_{\mathrm{id}}\right)\right) \times \mathrm{X}_{\mathrm{idv}}^{2} \quad \forall \mathrm{d} \in \mathrm{Dh}, \forall \mathrm{v} \in \mathrm{V}\right.$

$$
\begin{array}{ll}
\mathrm{Twh}_{\mathrm{dv}}^{1} \leq \mathrm{Tl} & \forall \mathrm{d} \in \mathrm{D}, \forall \mathrm{v} \in \mathrm{V} \\
\mathrm{Twh}_{\mathrm{dv}}^{2} \leq \mathrm{Tl} & \forall \mathrm{d} \in \mathrm{D}, \forall \mathrm{v} \in \mathrm{V} \\
\mathrm{Twh}_{\mathrm{hv}}^{1} \leq \mathrm{Th} & \forall \mathrm{h} \in \mathrm{H}, \forall \mathrm{v} \in \mathrm{V} \\
\mathrm{Twh}_{\mathrm{dv}}^{2} \leq \mathrm{Th} & \forall \mathrm{d} \in \mathrm{H}, \forall \mathrm{v} \in \mathrm{V}
\end{array}
$$

The Objective function of this problem is to minimize the total distribution cost, including vehicle usage cost in equation (1) and transportation cost in equation (2). Constraint (3) ensures that each customer and supplier is served only one time. Constraint (4) ensures that every vehicle comes to and leaves the customer afterward. Constraint (5) confirms that each vehicle returns to its respective DC. Constraint (6) agrees that each vehicle departs from DC. Constraint (7) ensures that every vehicle's initial load does not exceed the capacity. Constraint (8) ensures that every vehicle's last load does not exceed the capacity.

Constraints (9)-(12) approve that every route does not violate the time windows. Constraint (9) calculates the arrival time at a customer or supplier's place if the vehicle departs from the DC. Constraint (10) calculates the arrival time at the customer's or supplier's place if the vehicle departs from another customer or supplier. Constant $M$ in 
constraints (9) and (10) prevents the unselected route that violates the time windows. If a specific route is not selected, the value of $X_{d j v}$ or $X_{i j v}$ is 0 . Hence, M will become a considerable deduction, and the constraint will not be violated. Constraint (11) guarantees that every vehicle does not depart before the earliest departure schedule. Constraint (12) ensures that every vehicle arrives at the customer's and supplier's place at the range of the time windows. Constraints (13)-(15) are the additional constraints from the previous model. Constraint (13) ensures that picking up the goods from the suppliers is to be carried out after the vehicle finishes the shipment to the customer. Constraint (14) prevents the vehicle from stopping at another depot while shipping the goods to the customer. Constraint (15) is a sub-tour elimination constraint.

Constraints (16)-(19) are the model's novelty to ensure that the proposed lead time is achieved. Constraint (16) calculates the arrival of each vehicle at DC. Constraint (17) determines the latest arrival of the vehicle at DC. Constraint (18) estimates the earliest departure time of each vehicle at every DC, using the Tmd plus the sorting time at the depot. Constraint (19) calculates the latest arrival time of the vehicle at the hub. The latest arrival time is calculated by adding the Tmax with the processing time of the shipped goods via direct shipping. If there is a direct delivery between DCs, the number of goods that need to be processed by the hub decreases. Therefore, the time limit of the hub becomes shorter. If the Tmax is 23.00 and 60 goods shipped via direct shipping with sorting time of each good is one minute, this is 24.00 (23.00 plus sixty minutes). Constraints (20) and (21) guarantee that the goods moved from DC d to d' equal to the demand needed to be moved from DC $d$ to $d$ '. Constraint (22) is the capacity constraint for immediate shipping. In direct shipping, the vehicle that departs to another DC will come back with the goods from the destination to its respective DC. Also, the capacity of the vehicle needs to be considered for both directions. Constraint (23) is the capacity constraint for shipment via a hub. Constraint (24) ensures a different vehicle requirement in the shipment for both directions; it becomes the essential requirement for directions.

Constraints (25) and (26) ensure that all small and big vehicles return to their respective DC. Constraints (27) and (28) ensure that all small and big vehicles only leave DC once. Constraints (29) and (30) calculate the arrival time of each vehicle at DC. Vdv is an auxiliary variable that helps to identify the initial DC of each vehicle. Suppose the vehicle departs from the initial DC. In that case, the arrival time will be calculated using the earliest departure time from the DC plus the traveling time. Otherwise, the arrival time will be calculated using the vehicle's arrival time at the DC plus service and traveling time. Constraints (31) and (32) guarantee that every vehicle arrives at DC before the latest arrival time allowed. Constraints (33) and (34) ensure that each vehicle arrives at the hub before the latest arrival time that is permitted at the hub.

\subsection{Data and Experimental Procedures}

The model implemented in this study consisted of three DCs, eight customers, and four suppliers. It was inspired by a real case on the automotive wholesale company in Indonesia as it owns four different suppliers and three DCs. Table 1 describes the distance between hub, depot, customers, and suppliers. Nodes 1-3 were the DCs, nodes 4-11 were the customers, and 12-15 were the suppliers. With the velocity assumption of $40 \mathrm{~km} / \mathrm{hour}$, the traveling time between the nodes was calculated. Each customer had different demand, as described in Table 2.

Each supplier had different quantities of goods that need to be taken, as described in Table 3. The demands are shown in Table 2 and Table 3 (unit measurement in box). 
Each customer and supplier had a specific time window. Time windows described the earliest and the latest arrival time of each customer and supplier. The vehicle was not allowed to arrive after the arrival service time; but, it was allowed to come before the earliest arrival time and wait until the initial arrival time. Table 4 was time windows and service time for each supplier and customer. The departure time for each vehicle from each DC was 8 AM. There was a distance between hub and depot.

Table 5 illustrates the gap between hub and depot. It shows that nodes 1-3 were DCs, and node 4 was the hub. The unit measurement employed in this table was kilometers. There was a quantity of transit between the DCs. Table 6 describes the quantity of transit between the DCs. There was a time limit on each DC and hub. The vehicle was not allowed to arrive at DC and hub after the time limit.

Table 7 shows the time limit on each DC and hub. The gas cost for the small vehicle was IDR $980 / \mathrm{km}$ and IDR 1,250 for the big one. Usage cost for the small vehicles was as much as IDR 150,000 and IDR 225,000 for big vehicles.

Table 1. Distance Data

\begin{tabular}{cccccccccccccccc}
\hline Node & 1 & 2 & 3 & 4 & 5 & 6 & 7 & 8 & 9 & 10 & 11 & 12 & 13 & 14 & 15 \\
1 & 0 & 160 & 175 & 60 & 75 & 55 & 273 & 265 & 250 & 270 & 292 & 95 & 90 & 300 & 280 \\
2 & 200 & 0 & 150 & 260 & 275 & 255 & 73 & 65 & 50 & 270 & 292 & 295 & 290 & 100 & 280 \\
3 & 200 & 230 & 0 & 260 & 275 & 255 & 273 & 265 & 250 & 70 & 92 & 295 & 290 & 300 & 80 \\
4 & 60 & 260 & 260 & 0 & 45 & 40 & 195 & 200 & 190 & 245 & 265 & 60 & 55 & 255 & 320 \\
5 & 75 & 275 & 275 & 45 & 0 & 30 & 210 & 220 & 225 & 230 & 255 & 45 & 65 & 265 & 280 \\
6 & 55 & 255 & 255 & 40 & 30 & 0 & 180 & 190 & 200 & 270 & 280 & 50 & 40 & 280 & 290 \\
7 & 273 & 73 & 273 & 195 & 210 & 180 & 0 & 60 & 40 & 200 & 190 & 250 & 230 & 60 & 280 \\
8 & 265 & 65 & 265 & 200 & 220 & 190 & 60 & 0 & 35 & 210 & 195 & 230 & 220 & 50 & 270 \\
9 & 250 & 50 & 250 & 190 & 225 & 200 & 40 & 35 & 0 & 200 & 180 & 220 & 200 & 45 & 300 \\
10 & 270 & 270 & 70 & 245 & 230 & 270 & 200 & 210 & 200 & 0 & 30 & 200 & 210 & 230 & 50 \\
11 & 292 & 292 & 92 & 265 & 255 & 280 & 190 & 195 & 180 & 30 & 0 & 220 & 200 & 200 & 65 \\
12 & 95 & 295 & 295 & 60 & 45 & 50 & 250 & 230 & 220 & 200 & 220 & 0 & 40 & 240 & 260 \\
13 & 90 & 290 & 290 & 55 & 65 & 40 & 230 & 220 & 200 & 210 & 200 & 40 & 0 & 230 & 200 \\
14 & 300 & 100 & 300 & 255 & 265 & 280 & 60 & 50 & 45 & 230 & 200 & 240 & 230 & 0 & 210 \\
15 & 280 & 280 & 80 & 320 & 280 & 290 & 280 & 270 & 300 & 50 & 65 & 260 & 200 & 210 & 0 \\
\hline
\end{tabular}

Table 2. Customer Demand

\begin{tabular}{cc}
\hline Customer & Customer demand \\
\hline 4 & 30 \\
5 & 45 \\
6 & 40 \\
7 & 50 \\
8 & 35 \\
9 & 50 \\
10 & 43 \\
11 & 21 \\
\hline
\end{tabular}

Table 3. Supplier Demand

\begin{tabular}{cc}
\hline Supplier & Supplier Demand \\
\hline 12 & 70 \\
13 & 75 \\
14 & 65 \\
15 & 68
\end{tabular}


Table 4. Time Windows and Service Time

\begin{tabular}{ccc} 
Customer dan Supplier & Time Windows & Service time \\
4 & $9-12$ & 1 \\
5 & $12-15$ & 1 \\
6 & $13-16$ & 1 \\
7 & $8-13$ & 1 \\
8 & $10-15$ & 1 \\
9 & $12-16$ & 1 \\
10 & $9-14$ & 2 \\
11 & $11-14$ & 1 \\
12 & $15-18$ & 2 \\
13 & $13-16$ & 2 \\
14 & $13-16$ & 2 \\
15 & $13-15$ & 2 \\
\hline
\end{tabular}

Table 5. Distance Between Hub and DCs

\begin{tabular}{ccccc}
\hline & 1 & 2 & 3 & 4 \\
\hline 1 & 0 & 160 & 175 & 80 \\
2 & 160 & 0 & 150 & 87,5 \\
3 & 175 & 150 & 0 & 90 \\
4 & 90 & 87,5 & 90 & 0 \\
\hline
\end{tabular}

Table 6. In transit Quantity

\begin{tabular}{ccccc}
\hline & 1 & 2 & 3 & 4 \\
\hline 1 & 0 & 100 & 150 & 0 \\
2 & 120 & 0 & 160 & 0 \\
3 & 135 & 140 & 0 & 0 \\
4 & 0 & 0 & 0 & 0 \\
\hline
\end{tabular}

Table 7. Time Limit

\begin{tabular}{cc}
\hline DC & Time Limit \\
\hline 1 & 7.00 \\
2 & 7.00 \\
3 & 7.00 \\
$4(h u b)$ & 23.00 \\
\hline
\end{tabular}

The sensitivity analysis was performed with several parameters, such as usage cost of small and big vehicles, gas cost, and traveling time. The parameters were selected based on their effects on the model. The usage cost of small and big vehicles affected the route and the number of vehicles used. The traveling time affected the route and number of vehicles needed. The longer traveling time could increase the number of vehicles due to time window constraints. The sensitivity analysis was carried out for each parameter with change values of $-20 \%,-10 \%,+10 \%$, and $+20 \%$. One change parameter was used in one run. The case was solved using LINGO 1.0x64 bit. 


\section{Results and Discussion}

\subsection{Implementation}

The model was implemented in a case consisting of three DCs, eight customers, and four suppliers. The case needed 9 hours and 37 minutes of running time. The result can be seen in Fig. 1. The total cost generated for the routes is IDR 4,488,905.00.

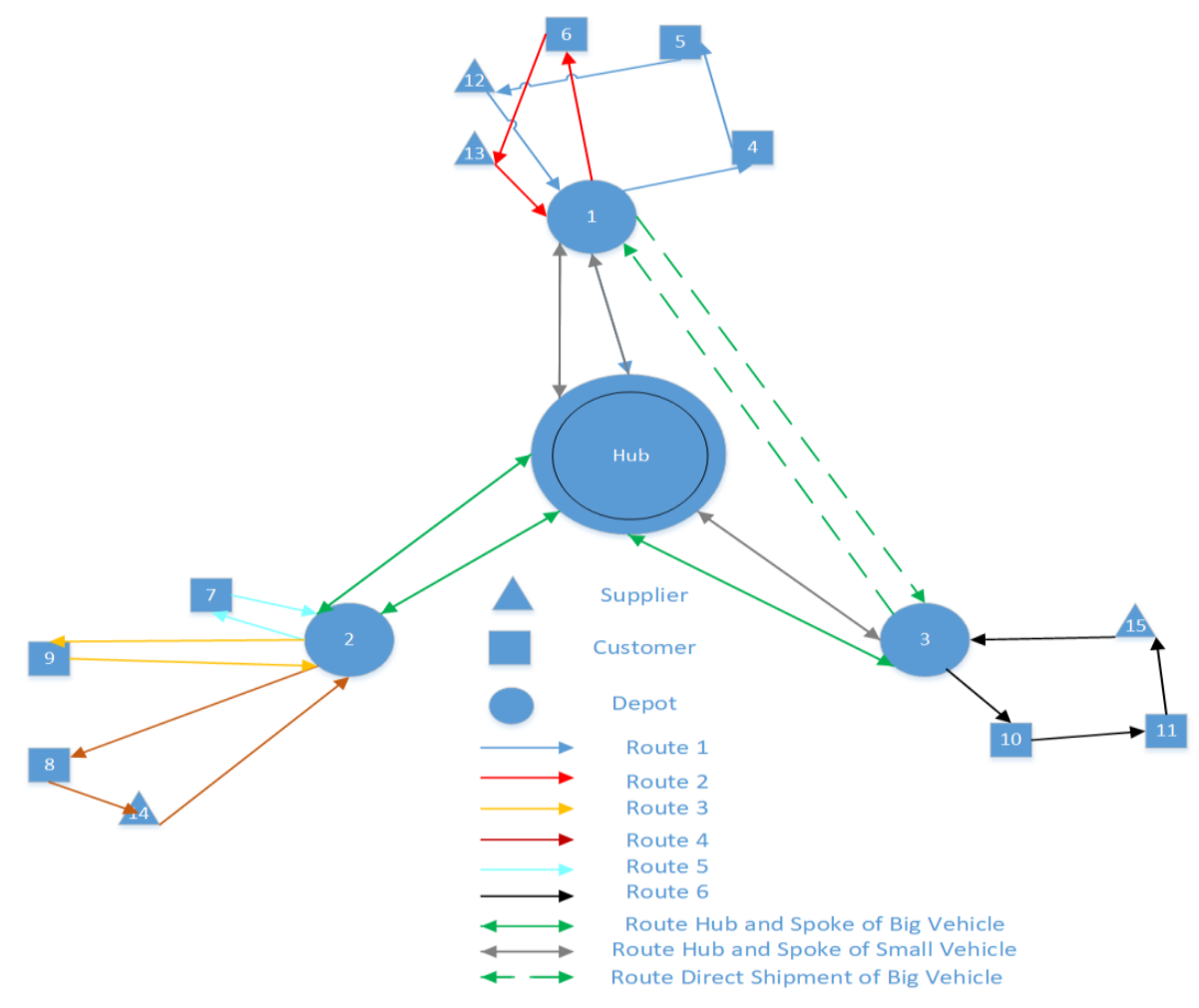

Fig. 1 The Solution Representation

\subsection{Sensitivity Analysis}

The Implementation of sensitivity analysis was carried out to determine the change in the solution that occurred when the input of the parameters was changed. Sensitivity analysis was performed by changing certain parameters. Several parameters were changed. The modified parameters were vehicle usage cost for small vehicles, vehicle usage cost for big vehicles, gas cost, and traveling time. Before commencing the sensitivity analysis, the researchers operated the program several times with the change of parameters. The result of sensitivity analysis is given in Table 8.

The researchers found that the increase in the usage cost of small vehicles is followed by an increase in the total cost needed. However, the number of small and large vehicles used does not change. Meanwhile, there is also a change in the number of small and large vehicles where significant vehicle usage decreases and the number of small vehicles increases. An increase follows the increase in the usage cost of big vehicles in the total costs. The substitution of one large vehicle also follows it into two small vehicles as they have a lower cost. While the decrease in the cost of using large vehicles only reduces the total cost, the number of vehicles used is still the same.

Changes in fuel costs per $\mathrm{km}$ have the most significant impact as compared to other parameters. Increasing fuel cost per $\mathrm{km}$ by $20 \%$ raises an increase in the total costs of 
$8.57 \%$. Also, a decrease in fuel cost per $\mathrm{km}$ by $20 \%$ causes a reduction in the total costs by $12.58 \%$. It proves that the Indonesian government's policy on fuel prices has a considerable influence on transportation costs. Changes in traveling time affect the solution if the traveling time increases by $20 \%$. Suppose the traveling time increases by $20 \%$ to satisfy the time windows. In that case, the number of significant vehicles needs to be added to cut the traveling distance of another vehicle. From all the factors, the fuel cost has the highest sensitivity to the solution. The distinction of this model with the previous model is that this model generates a route that makes sure all the vehicles arrive at each DC before the time limit.

Table 8. Sensitivity Analysis

\begin{tabular}{|c|c|c|c|c|}
\hline Percentage & $\begin{array}{r}\text { Vehicle Us } \\
\text { Total Cost (IDR) }\end{array}$ & $\begin{array}{l}\text { ge Cost of Sm } \\
\text { Quantity of } \\
\text { Big Vehicle }\end{array}$ & $\begin{array}{l}\text { ll Vehicle } \\
\text { Quantity of } \\
\text { Small Vehicle }\end{array}$ & Delta cost \% \\
\hline $20 \%$ & $4,670,865$ & 3 & 9 & $4.05 \%$ \\
\hline $10 \%$ & $4,568,905$ & 3 & 9 & $1.78 \%$ \\
\hline 0 & $4,488,905$ & 3 & 9 & $0.00 \%$ \\
\hline$-10 \%$ & $4,252,780$ & 2 & 11 & $-5.26 \%$ \\
\hline$-20 \%$ & $4,101,500$ & 2 & 11 & $-8.63 \%$ \\
\hline Percentage & $\begin{array}{r}\text { Vehicle L } \\
\text { Total Cost (IDR) }\end{array}$ & $\begin{array}{l}\text { age Cost of Bi } \\
\text { Quantity of } \\
\text { Big Vehicle }\end{array}$ & $\begin{array}{l}\text { Vehicle } \\
\text { Quantity of } \\
\text { Small Vehicle }\end{array}$ & Delta cost $\%$ \\
\hline $20 \%$ & $4,597,780$ & 2 & 11 & $2.43 \%$ \\
\hline $10 \%$ & $4,553,780$ & 2 & 11 & $1.45 \%$ \\
\hline 0 & $4,488,905$ & 3 & 9 & $0.00 \%$ \\
\hline$-10 \%$ & $4,422,905$ & 3 & 9 & $-1.47 \%$ \\
\hline$-20 \%$ & $4,353,905$ & 3 & 9 & $-3.01 \%$ \\
\hline Percentage & Total Cost (IDR) & $\begin{array}{l}\text { Gas Cost } \\
\text { Quantity of } \\
\text { Big Vehicle }\end{array}$ & $\begin{array}{c}\text { Quantity of } \\
\text { Small Vehicle }\end{array}$ & Delta cost $\%$ \\
\hline $20 \%$ & $4,873,686$ & 3 & 9 & $8.57 \%$ \\
\hline $10 \%$ & $4,636,296$ & 3 & 9 & $3.28 \%$ \\
\hline 0 & $4,488,905$ & 3 & 9 & $0.00 \%$ \\
\hline$-10 \%$ & $4,161,515$ & 3 & 9 & $-7.29 \%$ \\
\hline$-20 \%$ & $3,924,124$ & 3 & 9 & $-12.58 \%$ \\
\hline Percentage & Total Cost (IDR) & $\begin{array}{l}\text { caveling Time } \\
\text { Quantity of } \\
\text { Big Vehicle }\end{array}$ & $\begin{array}{c}\text { Quantity of } \\
\text { Small Vehicle }\end{array}$ & Delta cost $\%$ \\
\hline $20 \%$ & $4,713,050$ & 4 & 9 & $4.99 \%$ \\
\hline $10 \%$ & $4,488,905$ & 3 & 9 & $0.00 \%$ \\
\hline 0 & $4,488,905$ & 3 & 9 & $0.00 \%$ \\
\hline$-10 \%$ & $4,488,905$ & 3 & 9 & $0.00 \%$ \\
\hline$-20 \%$ & $4,488,905$ & 3 & 9 & $0.00 \%$ \\
\hline
\end{tabular}

This research only considers two cost factors, that is, vehicle usage cost and transportation cost. Many other cost factors may appear in this case, such as waiting time cost, late delivery/ pick up cost, and material handling cost. This model only allows customers to be served by one vehicle; if it is allowed to use more than one vehicle, it may enhance the vehicle utility and reduce costs. 


\section{Conclusion}

This research aims to develop a model to determine the route for hybrid hub-andspoke with time windows. The researchers developed a hybrid hub-and-spoke model with time windows to determine the inbound and outbound distribution routes. This model was designed using the Vehicle Routing Problem with Backhaul and Time Windows (VRPBTW) model and Hybrid hub-and-spoke as the basis for the modeling. Modifications are added to calculate time limits in the hub, calculation of vehicle departure time from the depot. Several additional constraints, such as sub tour elimination constraints, route restrictions, and other constraints, are also added. The results show that the model can solve the problem correctly. The suggestion For further research is to develop a model that allows a multi-pickup on suppliers and implement it in the actual case.

\section{References}

[1] A. Lewis, A. Lagrange, D. Patterson, and N. Gallop, "South London freight consolidation centre feasability study-Final report," London, UK: TTR, 2007.

[2] G. B. Dantzig and J. H. Ramser, "The Truck Dispatching Problem," Management Science, vol. 6, pp. 80-91, 1959. https://doi.org/10.1287/mnsc.6.1.80.

[3] A. Imran and L. Okdinawati, "Adaptation of the variable Neighborhood search heuristic to solve the vehicle routing problem," Jurnal Teknik Industri, vol. 12, pp. 10-15, 2012. https://doi.org/10.22219/JTIUMM.Vol12.No1.10-15.

[4] P. Toth and D. Vigo, "The Granular Tabu Search and Its Application to the VehicleRouting Problem," INFORMS Journal on Computing, vol. 15, pp. 333-346, 2003. https://doi.org/10.1287/ijoc.15.4.333.24890.

[5] C. Shi, T. Li, Y. Bai, and F. Zhao, "A heuristics-based parthenogenetic algorithm for the vrp with potential demands and time windows," Scientific Programming, vol. 2016, 2016. https://doi.org/10.1155/2016/8461857.

[6] N. A. El-Sherbeny, "Vehicle routing with time windows: An overview of exact, heuristic and metaheuristic methods," Journal of King Saud University - Science, vol. 22, pp. 123-131, 2010. https://doi.org/10.1016/j.jksus.2010.03.002.

[7] R. Liu and Z. Jiang, "A hybrid large-neighborhood search algorithm for the cumulative capacitated vehicle routing problem with time-window constraints," Applied Soft Computing, vol. 80, pp. 2019. https://doi.org/10.1016/j.asoc.2019.03.008.

[8] D. A. P. Putri, "Vehicle Routing Problem Dengan Time Window Untuk Multiple Product Dan Multiple Route Menggunakan Algoritma Sequential Insertion," Jurnal Teknik Industri, vol. 17, pp. 22-23, 2017. https://doi.org/10.22219/JTIUMM.Vol17.No1.22-30.

[9] L. Lin and L. Tao, "Solving Mixed Vehicle Routing Problem with Backhauls by Adaptive Memory Programming Methodology," in 2011 Third International Conference on Measuring Technology and Mechatronics Automation, 2011, pp. 310313. https://doi.org/10.1109/ICMTMA.2011.648.

[10] M. Goetschalckx and C. Jacobs-Blecha, "The vehicle routing problem with backhauls," European Journal of Operational Research, vol. 42, pp. 39-51, 1989. https://doi.org/10.1016/0377-2217(89)90057-X.

[11] R. Tavakkoli-Moghaddam, A. R. Saremi, and M. S. Ziaee, "A memetic algorithm for a vehicle routing problem with backhauls," Applied Mathematics and Computation, vol. 181, pp. 1049-1060, 2006. https://doi.org/10.1016/j.amc.2006.01.059.

[12] H. Koch, A. Bortfeldt, and G. Wäscher, "A hybrid algorithm for the vehicle routing problem with backhauls, time windows and three-dimensional loading 
constraints," $\quad$ OR Spectrum, vol. 40, pp. 1029-1075, 2018. https://doi.org/10.1007/s00291-018-0506-6.

[13] M. A. Ilgin and S. M. Gupta, Reverse logistics, 2013.

[14] M. E. Çiftçi and M. Şevkli, "A new hub and spoke system proposal: A case study for Turkey's aviation industry," Journal of Air Transport Management, vol. 47, pp. 190-198, 2015. https://doi.org/10.1016/j.jairtraman.2015.06.003.

[15] M. Zhalechian, S. A. Torabi, and M. Mohammadi, "Hub-and-spoke network design under operational and disruption risks," Transportation Research Part E: Logistics and Transportation Review, vol. 109, pp. 20-43, 2018. https://doi.org/10.1016/j.tre.2017.11.001.

[16] F. Alkaabneh, A. Diabat, and S. Elhedhli, "A Lagrangian heuristic and GRASP for the hub-and-spoke network system with economies-of-scale and congestion," Transportation Research Part C: Emerging Technologies, vol. 102, pp. 249-273, 2019. https://doi.org/10.1016/j.trc.2018.12.011.

[17] J.-H. Lee and I. Moon, "A hybrid hub-and-spoke postal logistics network with realistic restrictions: A case study of Korea Post," Expert Systems with $\begin{array}{lllll}\text { Applications, } & \text { vol. } & 41, & \text { pp. } & 5509-5519,\end{array}$ https://doi.org/10.1016/j.eswa.2014.02.027.

[18] W. Chen, K. He, and X. Fang, "Optimization of hybrid hub-and-spoke network operation for less-than-truckload freight transportation considering incremental quantity discount," Mathematical Problems in Engineering, vol. 2014, 2014. https://doi.org/10.1155/2014/830632.

[19] X. Yan, W. Jinghui, and Z. Liqun, "An Express Transportation Model of Hub-andSpoke Network with Distribution Center Group," Berlin, Heidelberg, 2013, pp. 467 472. https://doi.org/10.1007/978-3-642-33030-8_75.

[20] J. Liu, C.-L. Li, and C.-Y. Chan, "Mixed truck delivery systems with both hub-andspoke and direct shipment," Transportation Research Part E: Logistics and Transportation Review, vol. 39, pp. 325-339, 2003. https://doi.org/10.1016/S13665545(03)00005-X.

[21] J. Zhang, Y. Wu, and P. Liu, "Routing Problem for Hybrid Hub-and-spoke Transportation Network: a Case Study of a LTL Carrier," in 2007 IEEE International Conference on Automation and Logistics, 2007, pp. 170-175. https://doi.org/10.1109/ICAL.2007.4338551.

[22] G. Zäpfel and M. Wasner, "Planning and optimization of hub-and-spoke transportation networks of cooperative third-party logistics providers," International Journal of Production Economics, vol. 78, pp. 207-220, 2002. https://doi.org/10.1016/S0925-5273(00)00152-3. 